\section{The DR is out}

\section{By Lev Osherovich, Senior Writer}

Five years after a Genentech Inc. team proposed that the receptor DR6 might be involved in Alzheimer's disease, the company and The Rockefeller University have concluded that the proapoptotic pathway is unlikely to affect the most overt feature of the disease-amyloid plaque formation.

The Roche unit said that the new findings ${ }^{1,2}$ mark the stopping point for its discovery efforts to target DR6 (tumor necrosis factor receptor superfamily member 21 ; TNFRSF21) in AD. Although the company is backing off DR6, the academics involved in the work think further studies with better disease models are warranted.

DR6 is a member of a family of cell surface receptors that activates caspases-intracellular proapoptotic proteases-when neurons are deprived of trophic factors such as nerve growth factor (NGF) or brainderived neurotrophic factor (BDNF).

In 2009, Genentech discovered an interaction between DR6 and amyloid precursor protein (APP), ${ }^{3}$ a neuronal surface protein that undergoes a series of proteolytic cleavages to yield the $\beta$-amyloid (A $\beta$ ) fragment. A $\beta$ aggregates form the amyloid plaques that are the hallmarks of $\mathrm{AD}$ and are thought to be a main upstream trigger for neurodegeneration.

The group, led by then-CSO Marc Tessier-Lavigne, found that DR6 was activated by a fragment of APP left behind after the proteolytic processing formed $\mathrm{A} \beta{ }^{4}$

Tessier-Lavigne is now a professor and president at The Rockefeller University.

Because activation of DR6 by the stray APP fragment led to neuronal apoptosis, the next question was whether DR6 activation played a role in $\mathrm{A} \beta$ toxicity.

"We set out to test a specific hypothesis about the potential role of DR6 in an APP-driven model of AD," said team leader and Genentech senior scientist Robby Weimer. "The conclusion from our results is that we didn't find a role for DR6 in amyloid formation, synapse loss or behavior consequence. Our take home is that DR6 doesn't represent a good target for APP-driven AD pathology."

\section{Death receptor dead}

The hope was that DR6 inhibition might enhance neuronal branching and thus counteract the neurotoxic effects of $A \beta$. However, the new findings suggest that will not be the case.

In two mouse models of $\mathrm{AD}$ in which overproduction of $\mathrm{A} \beta$ leads to disease, DR6 deletion increased branching of mature neurons in some brain regions compared with no alteration. However, DR6 deletion did not reduce plaque formation or the behavioral and cognitive consequences of $A \beta$ toxicity.
Results were reported in The Journal of Neuroscience.

Weimer and Tessier-Lavigne said that the findings indicate that one of APP's normal functions outside of AD may be to interact with DR6 to control neuronal branching in the adult nervous system. However, this process likely occurs independently of the abnormal proteolytic processing of APP that leads to AD.

"It seems that APP has multiple functions," said Weimer. "Its normal physiological function could be through DR6. We did find evidence for DR6 and APP acting together in the mature nervous system to regulate synapse sensitivity."

Tessier-Lavigne said that the findings do not absolutely shut the door on DR6's role in AD. He noted that the mouse models did not display some key features of $\mathrm{AD}$ such as neurodegeneration.

Thus, he said that other models of neurodegeneration featuring abnormal expression and phosphorylation of microtubule-associated protein- $\tau$ (MAPT; tau; FTDP-17) are an alternative place to look for effects of DR6 deletion. Some of those models display clear patterns of axonal degeneration, a terminal stage of $\mathrm{AD}$ pathology.

"We need to understand the extent to which DR6 participates in axon degeneration in other preclinical models with frank axonal pathology," said Tessier-Lavigne. "For example, it would make sense to study the DR6 knockout in the context of some tauopathy models."

Last year, Tessier-Lavigne's team and collaborators reported that in an assay of neuronal growth, adult DR6 knockout mice had less axonal degeneration than wild-type controls. ${ }^{5}$

Tessier-Lavigne said that his team now is investigating how DR6 affects axonal degeneration using induced pluripotent stem (iPS) cells from patients with $\mathrm{AD}$ and another common neurodegenerative disorder, frontotemporal dementia.

Weimer said that Genentech has discontinued its DR6 studies until a more solid connection to disease emerges. "At this point we're not planning any additional experiments" concerning DR6, said Weimer.

Genentech's most advanced AD candidate is crenezumab, a mAb that targets soluble or oligomeric A $\beta$. It was developed in partnership with AC Immune S.A. and is in Phase II testing to treat mild to moderate AD. Roche's gantenerumab, developed with MorphoSys AG, also targets $\mathrm{A} \beta$ plaques and is in Phase III testing for $\mathrm{AD}$.

Osherovich, L. SciBX 7(19); doi:10.1038/scibx.2014.546

Published online May 15, 2014

\section{REFERENCES}

1. Nikolaev, A. et al. Nature 457, 981-989 (2009)

2. Kallop, D.Y. et al. J. Neurosci.; published online May 7, 2014; doi:10.1523/JNEUROSCI.4963-13.2014

Contact: Robby M. Weimer, Genentech Inc., South San Francisco, Calif.

e-mail: weimer.robby@gene.com

3. Olsen, O. et al. J. Neurosci.; published online May 7, 2014; doi:10.1523/JNEUROSCI.3522-13.2014

Contact: Marc Tessier-Lavigne, The Rockefeller University, New York, N.Y.

e-mail: marct|@rockefeller.edu

4. Osherovich, L. SciBX 2(8); doi:10.1038/scibx.2009.300

5. Marik, S.A. et al. J. Neurosci. 33, 14998-15003 (2013) 


\section{ANALYSIS}

COMPANIES AND INSTITUTIONS MENTIONED AC Immune S.A., Lausanne, Switzerland Genentech Inc., South San Francisco, Calif.

\section{TARGETS \& MECHANISMS}

MorphoSys AG (Xetra:MOR; Pink:MPSYF), Martinsried, Germany Roche (SIX:ROG; OTCQX:RHHBY), Basel, Switzerland The Rockefeller University, New York, N.Y. 